\title{
Intentional and Phenomenal Properties: How not to be Inseparatists
}

\author{
Miklós Márton ${ }^{1}$ (iD
}

Received: 24 January 2019 / Revised: 12 March 2021 / Accepted: 15 March 2021 /

Published online: 10 April 2021

(c) The Author(s) 2021

\begin{abstract}
In this paper I give an overview of the recent developments in the phenomenalism - intentionalism debate and try to show that the proposed solutions of neither sides are satisfying. The claims and arguments of the two parties are rather vague and attribute to intentional and phenomenal properties either a too weak or a too strong relationship: too weak in the sense that they establish only mere coexistence, or too strong in the sense that they attribute some a priori conceptual connection to intentional and phenomenal properties. I also compare these theories to other theories developed for solving the mind-body problem and argue that these former are much less elaborated. In the end of the paper I try to explain that all of this is not just a contingent feature of the topic, but has deep conceptual roots: intentionality and phenomenal consciousness are two quite distinct concepts on two quite distinct levels.
\end{abstract}

Keywords Phenomenal consciousness · Intentionality · Phenomenal intentionality · Intentionalism

\section{Introduction}

In the last two or three decades, the main focus of analytic philosophy of mind has been on the question concerning the relationship of intentionality and phenomenal consciousness. As the traditional mind-body problem has started to lose attention in the nineties, the intentionalism-phenomenalism debate became central in this area of philosophy. There are roughly two main parties in this debate: the first group (e.g.: Dretske, Tye, Lycan, Byrne) tries to ground phenomenal properties in intentional properties, whereas the second group (e.g. Searle, Galen Strawson, Horgan, Loar, Kriegel, Mendelovici) attempts to base intentionality in phenomenality. In the following I use the terms 'intentionalism' and 'phenomenalism' to refer to these two groups, respectively.

Miklós Márton

marton@ajk.elte.hu

1 Faculty of Law, Center for Theory of Law and Society, Eötvös Loránd University Budapest, Bartók Béla street 52. B 2/2, Budapest, Hungary 1111 
The relationship between intentionality and phenomenality is interesting in itself, but even more is at stake. Here is a short list of some acute philosophical problems that are supposed to become answerable or at least, more tractable had we solved the problem concerning the relationship between these two properties.

1) The mark of the mental problem. Everybody knows the good old thesis of Brentano that all mental phenomena are intentional phenomena. Is this so? Or maybe the opposite thesis is right, namely that every mental phenomenon is a phenomenally conscious phenomenon? Or are both theses right? Or neither is? If neither thesis is right, then what would be the common feature in all phenomena called 'mental' in ordinary speech, what would make them really mental?

2) The mind-body problem. Many philosophers believe that intentionality can be naturalized by the help of some adequate - causal, teleological or functional theory. If this intuition is right and the Brentano thesis also holds, then one can convincingly argue for physicalism (or naturalism, if it makes any real difference) (see e.g.: Chudnoff, 2015).

3) The externalism - internalism debate. Many philosophers think that phenomenal properties are intrinsic properties of the subject who bears them. And some also think - as I noted - that at least some intentional features are grounded in phenomenal properties. Therefore, at least some intentional properties are intrinsic properties of the subject, which means that there is internal or narrow intentionality.

4) The problem of psychologism. If intentional properties (including intentional content) are based somehow on phenomenal character, and the latter is internal to the subject, that is, a psychological property, then intentional content is also a psychological property, in contrast to the famous claims of Frege and Husserl (see: Pitt, 2009).

5) The problem of determining content. Some phenomenalist thinkers claim that the problem of giving determinately the content or the object of an intentional state can be solved by alluding to phenomenal character. In the cases where it seems that there are too many possible intentional objects (as Quine or 'Kripkenstein' famously argued), or even if it seems that there are none, phenomenal character can decisively provide us the desired result (see: Kriegel, 2007; Chudnoff, 2015).

In the present paper I aim to cast doubt on these hopes. I will try to show that the claims and arguments of both the intentionalist and the phenomenalist parties are either vague or does not prove what they intend to prove. In the end of the paper I try to explain that this is not just an accidental feature of the debate and cannot be accounted for by the relative novelty of the topic, and I also try to point out, rather tentatively, what is the underlying reason of these failures.

\section{Vague Positions and Claims}

We can distinguish three logically possible views concerning the relationship of phenomenal and intentional properties. 
a) In the beginning there was separatism, which claimed that intentionality and phenomenality are independent, even separate properties of mental states. They are separated in the sense that there exist mental states, most prominently propositional attitudes, which are intentional, but not phenomenally conscious, and there exist other mental states, especially bodily sensations, which are phenomenally conscious, but not intentional. As David Rosenthal clearly put it:

There are two broad categories of mental property. Mental states such as thoughts and desires, often called propositional attitudes, have content that can be described by 'that' clauses. For example, one can have a thought, or desire, that it will rain. These states are said to have intentional properties, or intentionality. Sensations, such as pains and sense impressions, lack intentional content, and have instead qualitative properties of various sorts. (Rosenthal, 1994: 349.)

b) Indifferentism involves a weaker claim than separatism. It agrees with separatism in that intentionality and phenomenality are entirely independent properties, so each can be instantiated independently by a mental state, but it allows the coexistence of them: mental states, possible all of them, can instantiate both intentionality and phenomenality at the same time. The most salient example of such kind of mental states is sense experience, which has qualitative features just as intentional ones. One can justifiably say that there is something it is like to see/hear/smell something and, at the same time, that we can see/hear/smell that something is the case.

c) Moreover, partly by this consideration about the nature of sense experiences, more and more philosophers have become persuaded that phenomenal and intentional properties are not wholly independent of each other, but are interdependent; that is, the systematic co-occurrence of them is not a contingent, accidental feature of some (or all) mental states, but follows from their very nature. We can call this the necessary dependence view. One often quoted formulation of it is due to Colin McGinn who famously stated:

Thus perceptual experiences are Janus-faced: they point outward to the external world but they also present a subjective face to their subject: they are of something other than the subject and they are like something for the subject. But these two faces do not wear different expressions: for what the experience is like is a function of what it is of, and what it is of is a function of what it is like. Told that an experience is as of a scarlet sphere you know what it is like to have it; and if you know what it is like to have it, then you know how it represents things. The two faces are, as it were, locked together. The subjective and the semantic are chained to each other. (McGinn, 1988/1997: 298)

However, this necessary co-occurrence needs some explanation. There must be something in phenomenal consciousness, or in intentionality, or in both that makes the joint presence necessary. The most natural explanation of the necessary 
coexistence of these properties is that one is in some sense grounded in the other, or that the occurrence of one of the relata necessarily brings about the other (or that there is a third factor whose occurrence necessarily brings about both - I will ignore this possibility). One possible explanation is, of course, the identity of the two properties, perhaps with the claim that either the intentional or the phenomenal description is more fundamental.(see Mendelovici, 2018: 110, Bourget \& Mendelovici, 2019).

It is worth noting that the literature usually only contrasts separatism with inseparatism, whereby the latter position one means the necessary dependence view. One of my aims in the recent paper is to argue, however, that the third, indifferentist position should not be ignored.

If one claims that a strong relationship exists between phenomenal and intentional properties, it becomes an acute and urgent task to define accurately the nature of this relationship. In what sense is phenomenal character 'grounded in' intentionality, or vice versa? One can find a host of different and vague statements regarding this question in the relevant literature. Here are some examples (the keywords are italicized by me):

We affirm the following theses, both of which are repudiated by separatism:

The Intentionality of Phenomenology: Mental states of the sort commonly cited as paradigmatically phenomenal [...] have intentional content that is inseparable from their phenomenal character.

The Phenomenology of Intentionality: Mental states of the sort commonly cited as paradigmatically intentional [...], when conscious, have phenomenal character that is inseparable from their intentional content.

[...]

Phenomenal Intentionality: There is a kind of intentionality [...] that is constitutively determined by phenomenology alone.

We use the expression 'constitutively determined' to mean that this kind of intentionality is not merely nomically determined; rather, intentional mental states have such intentional content by virtue of their phenomenology. (Horgan \& Tienson, 2002)

The mark of a representational theory of phenomenal character is that it makes character covary with representational content with metaphysical necessity. (Kriegel, 2002: 193., fn20.)

A thought's having a particular representational content is its having a particular phenomenology. (Pitt, 2004: 6.)

The phenomenal character of $[\ldots]$ experiences $[\ldots]$ is likewise entirely determined by their propositional contents. (Byrne, 2001: 199.)

Two versions of pure intentionalism are sometimes distinguished: strong pure intentionalism, which says that the phenomenal character of a mental state is identical with its representational content [...], and weak pure intentionalism, which says that the phenomenal character of a state is determined by or supervenes on its representational content. (Crane, 2008)

The fact that $\mathrm{M}$ is conscious entails the fact that $\mathrm{M}$ has intentional content of kind K. [...] It is possible to hold, for instance, that even though M's con- 
sciousness is not exhausted by M's intentional content, it nonetheless necessarily involves an intentionality. (Kriegel, 2003: 272)

[S]ome mental states have a phenomenal property and an intentional property, such that $[. .$.$] the relevant intentional property is constituted (realized?) by$ the relevant phenomenal property [...]. [S]ome phenomenally conscious states are intentional, and intentional in virtue of being phenomenal. (Kriegel, 2007: 319)

[I]ntentionality is simply identical to phenomenal consciousness (Mendelovici, 2018: Xv.)

However, it would be of the utmost importance for an intentionalist or phenomenalist theorist to clearly state what kind of relationship she attributes to the two properties. It does matter what philosophical consequences one can draw from the established relationship.

\section{Lessons from the Mind-Body Problem}

As we could see from the above excerpts, the nature of the relationship between phenomenal and intentional properties can vary from casual coexistence to necessary a priori identity. This situation suggests a relevant analogy to the mind-body problem where fine-grained distinctions were elaborated between different kinds of relations between mental and physical properties. It is therefore worth taking a short survey of the ideas concerning this latter relationship.

1. Mere coexistence: From the fact that two properties contingently coexist sometimes, even always, in no way follows that one of them is more fundamental or can be grounded in the other. Even a psychophysical parallelist or an occasionalist can happily acknowledge that the two independent properties, namely the mental and the physical properties, can coexist.

2. Mere supervenience: The asymmetric relationship of supervenience is nothing more than a systematic coexistence, more exactly covariance. Therefore, no strong priority thesis follows from it, either. An interactionist Cartesian dualist or an epiphenomenalist can happily acknowledge that mental properties supervene (globally) on physical ones, namely in the way that physical events cause mental ones. She has to hold only that the 'same cause, same effect' thesis is valid, while the 'same effect, same cause' thesis is false, which is a plausible standpoint.

3. Supervenience with metaphysical necessity: This label covers kinds of relationships where mental properties not only supervene (globally) on physical ones, but the existence of the latter necessarily brings about the existence of the former. So, as it is usually stated, the minimal physical duplicate of our world is the exact duplicate of our world simpliciter. In this construction, the two kinds of properties remain different, nevertheless mental properties depend for their existence on physical properties. Moreover, this relationship can be known either by some a priori, or some a posteriori way. In the former case, physical properties 
a priori necessitate the mental ones. ${ }^{1}$ However, it is not entirely clear how can certain relations between distinct properties be metaphysically necessary. That is, are there really such relationships, except identity? Maybe 'constitution' and/ or 'realization' is such a relationship.

4. A posteriori identity: The most straightforward case of the dependence of mental properties on physical ones is when the mental properties are identical with physical ones. So, there are not two properties, but only one. Furthermore, on the level of predicates designating these properties, we can distinguish cases in which it is an empirical, a posteriori fact that the two terms refer to the same property and cases in which it can be established a priori.

5. A priori conceptual identity: In the cases where we can establish the identity of the two properties by a priori tools, the two predicates designating them are conceptually connected, even synonymous. In other words: one can establish the identity thesis only by investigating the semantic properties of the appropriate terms or concepts, therefore the identity claim one can get by this method is necessarily true, in the de dicto sense of the term.

It seems important to notice that empirical or introspective observation alone can not decide between these options. You cannot say merely on the basis of empirical evidences or pure introspection that the observed relation between mental and physical properties is of mere coexistence, supervenience or identity. For this purpose, you also need theoretical considerations, and the mind-body theorist do apply some in their argumentations (e. g. inference to the best explanation, Occam's razor, the plausibility of the causal closure of the physical world, etc.). Conversely, if two predicates were connected conceptually, then you need not conduct empirical or introspective investigations to establish that the corresponding properties are identical.

One way to think about the long story of the mind-body problem, especially the physicalist branch of it, is as a heroic quest for finding the adequate relationship which is stronger than mere supervenience, but weaker than a priori conceptual identity. A relationship which warrants the priority of physical properties over mental ones, but does not decide the question simply by verbal maneuvers. That is, the required relationship should guarantee that the occurrence of a certain physical property brings about a certain mental one with metaphysical necessity, while refrain from deciding the question merely by semantic considerations, or ad absurdum by definitions.

I think all this has to be true in the case of the relationship of phenomenality and intentionality as well. If we try to merge the two taxonomies into one, it is apparent that the taxonomy of the mind-body problem is much more finegrained. Moreover, the category of separatism has no corresponding category in the taxonomy of the possible mind-body relations, because it rules out even

\footnotetext{
1 It is notable that this kind of a priori physicalism is about the very properties, and not about words or concepts. Therefore, it is de re necessity to which the theory attributes the a priori status, rather than de dicto. So, in order to know a sentence about such relationship, you have to know (in some substantive sense of the term) the properties the appropriate predicates stand for. See: Jackson (2005)
} 
mere coexistence. I think the first two kinds of relationships correspond to indifferentism while the other three, the metaphysically necessary supervenience and the two kinds of identity, to the necessary dependence view. Now, similarly to the latter mentioned theories of the mind-body problem, if one wants to be a strong inseparatist and ground one of the above properties (intentionality and phenomenality) in the other, then one has to establish such a relationship between them which does not allow their metaphysical independence from each other, but necessitates their relationship without connect them with some a priori conceptual link. With the above considerations in hand, in the following I try to point out that intentionalists and phenomenalists equally fail to get the required relationship. If we get ourselves through the vague phrasings, it turns out that their standpoints and arguments are either too weak in the sense that they establish only mere coexistence or supervenience, or too strong in the sense that they decide the question by a priori conceptual or semantical considerations.

\section{Intentionalism}

The older view from the two opposite standpoints is intentionalism, or as frequently called, representationalism. The essence of this view is the claim that phenomenal properties, especially the phenomenal character of an experience, somehow depends on the intentional properties of the same experience. Let's see what are the arguments for this and how they are supposed to work!

The main argument for intentionalism draws on the transparency of experience, that is, on a phenomenological feature of our experiences. As it was mentioned earlier, sense experiences are the paradigm cases where intentional and phenomenal properties systematically coexist. However, when we have a sense experience, it seems we are always aware only of the perceived object or property, even if we try to concentrate on the experience itself. The specific shade of color, which we see, seems to belong to the seen object, not to our visual experience. We are never aware of some properties or features of the experience itself with the help of which we experience the perceived object. To use Gilbert Harman's famous phrase (Harman, 1990), in the experience - in contrast to real paintings - there is no 'mental paint', that is, during sense experiences we have no access to the vehicles of representation, only to the representational properties themselves. And this is the point on which intentionalism relies: only the representational properties are salient phenomenologically, thus what it is like for us to undergo such an experience must depend on the representational properties of the experience. For example, here is how Michael Tye describes the argument for intentionalism from the introspective fact of transparency:

[I]ntrospection of your perceptual experiences seems to reveal only aspects of what you experience, further aspects of the scenes, as represented. Why? The answer, I suggest, is that your perceptual experiences have no introspectible features over and above those implicated in their intentional contents. So the 
phenomenal character $[\ldots]$ of your experience - certainly something you are introspectively aware of on such an occasion - must itself be representational. (Tye, 1995: 136., italics in the original).

According to the intentionalist theorist, this feature of transparency can be detected not only in sense experiences, but also in other kinds of mental states. Some of these thinkers (e.g. Byrne, 2001; Crane, 2001; Tye, 1995) have made serious efforts to show that bodily sensations, afterimages, emotions, even seemingly objectless moods have also intentional features which serve as the basis of the salient phenomenal characters of these states. For example, Tim Crane and Alex Byrne argue that the felt locations of bodily sensations give us good reason to attribute intentionality to these states. Some sensations have exact small body-parts as felt locations (for example pains in the limbs), some have larger parts (for example nausea), and some have the whole body as felt location (for example distress) (see: Crane, 2001: 79-80., Balogh \& Tőzsér, 2013: 50-53.). Felt locations must not be identified with a real part of the body in order to account for the phenomena of phantom pains. Moods and emotions in turn must be endowed with intentionality on the basis of their causes (see: Crane, 2008: 28). Moreover, the other aspect of these arguments is that the intentionality of these mental states is also transparent. You do not feel your toothache as belonging to your pain-experience; rather, you feel it belonging to your teeth. So just as in the case of sense experiences, the well-known phenomenal character of a toothache must be grounded in the representational properties of the pain-experience.

What gives importance to these efforts is partly the fact that if these theorists were to be successful in their endeavor, then they would succeed in showing that not just propositional attitudes and sense experiences, but every mental state has intentional properties. However, if that was all what intentionalists can show, it would be no more than justifying a ubiquitous co-occurrence of phenomenal and intentional properties. The arguments would be surely insufficient to justify the priority of intentional properties. Strictly speaking, what the argument from transparency really shows is merely that there is only one kind of properties present in the experience, not two. Therefore, the argument states an identity thesis, namely, that the two kinds of properties are the same. This position sometimes called 'strong intentionalism' in contrast to 'weak intentionalism', which states only a supervenience thesis. So, the argument from transparency allegedly shows that we have only one kind of properties, namely representational ones, but it does not show that we couldn't describe them equally well as phenomenal properties. But how can we know that phenomenal and representational are identical, i.e. that they are not two distinct kinds in reality? And if they are indeed identical, how can we know that the representational way of description is the more adequate, more fundamental one? ${ }^{2}$ It is telling that one and the same argument from transparency is used also by phenomenalist theorists, trying to establish their fundamental thesis about the priority of phenomenal consciousness (see: Horgan \& Tienson, 2002, Kriegel, 2007: 320).

\footnotetext{
2 Cf.: "since identity is not asymmetric, some versions of representationalism and PIT [Phenomenal Intentionality Theory] taking the relevant arising relations to be identity relations are compatible with each other." (Mendelovici \& Bourget, 2020: 565.).
} 
I think serious doubts can be raised about the success of this kind of argumentation. Firstly, the argument for intentionalism from transparency on introspective grounds is a phenomenological argument. Nevertheless, it apparently tries to persuade us about a metaphysical thesis, namely that the phenomenal properties of an experience are identical with its representational properties. However, we have seen in the case of the mind-body problem that neither empirical nor introspective observation can decide whether the relationship in question is coexistence, supervenience by realization, or identity. In the same vein, the argument from transparency in itself cannot distinguish between the different kinds of relationships resulting in necessary metaphysical dependence (e. g. between identity or metaphysically necessary supervenience). It merely shows that we cannot get two different groups of properties by relying only on our experiences or on the introspective observation of them. ${ }^{3}$

Secondly, and more importantly, while introspective observation can persuade us that there are not two kinds of properties that are present in an episode of experience, it also cannot decide which description we should choose to refer to this kind of properties. Why must we think that it is a representational, rather than a phenomenological one? Tye's 'aspects of what you experience' formulation in the above quotation presupposes his conclusion, namely that the only revealed properties are that of the experienced object rather than of the episode of experience. In other words: the transparency of experience only entails that a single kind of property is present in an act of experience, namely the qualitative properties you are conscious of during the episode of experience. ${ }^{4}$ Let's call them qualia. However, at this point the following question remains open: do these qualia belong to the experienced object (as intentionalists suppose), and so are they representational properties of the experiential state, or do they belong to the subject of experience as something the experience is like to be for her? To say that the transparency of experience shows that perceptual experience reveals only the properties of the thing perceived, is, to my mind, nothing more than choosing the first option without any argument. This formulation is not a neutral description, but rather an interpretation of the phenomenological fact. There are theories of perceptual experience that are based on the same phenomenological data, however committed to the opposite view, namely that perceptual experiences do not have first-level representational properties: what appears to the subject during a sensory experience are not the properties of the mind-independent world, or its representations, but only the intrinsic properties of the experience itself. They obtain representational function only by some systematic interconnections of them (see for example: Farkas, 2013). I think the mere possibility or the more or less prima-facie plausibility of these theory is enough to establish the above claim. In sum: it is not enough to allude to introspective facts; the intentionalist has to give other theoretical arguments in order to establish that the intentional description is the more adequate,

\footnotetext{
3 Fort the difficulties of leaning solely on introspection in answering questions concerning the relation between phenomenal and intentional properties in the case of cognitive episodes, see (Chudnoff 2015: 24-27.).

4 For a similar conclusion see Mendelovici (2018: 95.).
} 
and therefore, that representational properties are more fundamental. Without such an argumentation she cannot successfully argue for the priority of intentional properties over phenomenological properties. ${ }^{5}$

At this point, some intentionalist theorists try to exceed mere contingent coexistence and to establish the primacy of intentional properties by connecting conceptually the two kinds of properties. What they call the intentionality of an experience is nothing more than 'how the world seems to the subject' during the experience, or 'what perspective has the subject on the world'. (see: Crane, 2001; Byrne, 2001: 201-02.) And it is impossible to describe how the world seems to us without describing the object of experience and the way this object presents itself to me. Alex Byrne argues in this vein, when he claims that there can be no zombies whose experiences have the same intentional properties as ours, but lack any phenomenal character. According to him, if these beings have no phenomenal properties, that is, it will be nothing it is like to be them, then the world will seem to them in no way (Byrne, 2001: 232-33.). In a word, this move connects the two predicates conceptually, as Tim Crane nicely expresses it:

Now it is certainly plausible to say that 'the way things seem to the subject' can be read as a synonym for the content of an experience. But someone [...] can say that the 'way things seem to the subject' can be read in another way too: it can pick out aspects of the phenomenal character of the experience itself. It could be said that when one experiences something, the world seems a certain way to the subject; but in addition, having the experience also seems a certain way: 'things' covers both aspects of this seeming. (Crane, 2008: 484., italics in the original)

As I understand it, this and similar passages claim that the intentional and phenomenal properties of an experience are necessary identical, and the difference between them is nothing more than the difference of 'aspects' or 'readings'. The phrase 'the way things seem to the subject' is synonymous both with representational and phenomenological properties of the experience, therefore they are synonymous with each other, too. Consequently, we need not apply empirical or introspective methods in order to establish this necessary identity, because the two predicates are conceptually connected. ${ }^{6}$ See for example this other excerpt from Crane which can be found a few paragraphs below the previous one: "the best explanation of the fact that the notions of how things seem and how things are represented to be are so close to one another, it seems to me, is that they have a common core." (Crane, 2008: 487.)

\footnotetext{
5 The same point is formulated by Bailey \& Richards (2014). In connection to phenomenalism they write that "if the phenomenal and the phenomenal intentional vary together then what sense can we make of the claim that one is prior to the other? In particular, what could support [... the] assertion that the phenomenal grounds and»constitutes « the phenomenal intentional rather than, as the representationalist might hold, the other way around?" (Bailey \& Richards, 2014: 318.).

6 I suppose that these authors do not write merely about the coincidence of the relevant linguistic expressions, behind which one can find different concepts. I do not think they see the whole problem as rooting in the insufficiency of our ordinary natural language.
} 
Let us approach this from another point of view. Most intentionalists try to determine what kinds of intentional properties serve as the basis of, or are identical with phenomenal properties. Pure intentionalists (e.g. Tye, 1995) say that the relevant intentional content is sufficient to play this role. By contrast, impure intentionalists claim that the intentional content plus the intentional mode - the way a content is given to the subject - are needed. The defenders of this latter view argue that the same content can be represented in many different ways, for example by different sense modalities, which probably yield different phenomenal characters (see: Byrne, 2001: 205., Crane, 2008). Moreover, it is frequently argued that each type of intentional content can be represented unconsciously, so content in itself cannot yield phenomenal characters (see: Chalmers, 2004: 157., Lycan, 2008). Therefore, it is argued, we have to choose impure intentionalism, and state that not just the content, but also the intentional mode is needed to get phenomenal character. But what does this mode add to the content which makes it plausible that it results in a determinate phenomenal character? How should I represent a content to be in a state which is something it is like to me? The answer is: I have to represent the content in a phenomenal way. To undergo an experience with such and such phenomenological character is nothing more than representing a content in such and such phenomenological mode. However, this formulation clearly entails phenomenal character, because in specifying what does this 'phenomenal way' mean in a concrete case, we can't escape alluding to the phenomenal character, which we are trying to explain (see: Chalmers, 2004: 160-162). So, we have found again that the two predicates are conceptually connected to each other.

I think this solution of the problem - namely to connect intentional and phenomenal properties conceptually - has unacceptable consequences. First of all, and most importantly, this consideration turns the intentional description of the experience into a phenomenological one: how the world and the perceived object seem to me implies conceptually that I am phenomenally conscious of these features. Consequently, this consideration establishes an a priori conceptual connection between the two kind of properties, which, to my mind, is not an adequate solution to our problem. I am going to return to this question below (in the Conclusion section).

The next consequence of the mentioned solution is that it rules out unconscious intentional states. When we apply the above concept of intentionality to unconscious intentional states, it follows that the world seems to me somehow unconsciously, which sounds absurd. On the other hand, ruling out unconscious intentionality without any compromise seems as absurd as the former possibility.

Lastly, if the two properties stand in such a conceptual relation as we saw above, then introspective observations of our mental states will be entirely superfluous. In this case you can conceptually deduce phenomenal properties from intentional properties without alluding to the transparency or other phenomenal features of experience. I am not sure that this is the result desired by intentionalists.

In sum, it appears to me that if the intentionalist - depending on the argument from transparency - argues only for the thesis that every mental state, including the phenomenally conscious states, have transparent intentional properties, then this 
move shows only a contingent co-occurrence of the two kinds of features, without any strong claim of interdependence or priority. This position rather fits the indifferentist view, which is obviously too weak for supporting intentionalism. On the other hand, if by the argument she wanted to reach priority of intentional properties, and in virtue of it some stronger metaphysical relationship, then she actually states an a priori-conceptual identity claim about intentionality and phenomenal consciousness, which is an overly strong.

\section{Phenomenalism}

The other standpoint in the debate is more recent, and perhaps not as widely known as intentionalism. Phenomenalists claim that intentionality or intentional content represent a form of phenomenal consciousness, or can be derived from it. Or, more cautiously, they say that there is a kind of intentionality, namely phenomenal intentionality, which is a form of, or derivative from, consciousness, and all other kind of intentionality stem from this somehow. This is the core of the Phenomenal Intentionality Thesis (PIT). I take phenomenalism as equivalent to the strong or moderate version of PIT - as it is characterized by for instance Bourget and Mendelovici (Bourget \& Mendelovici, 2019) -, and I will not take into account the weak version of it, according to which only some intentional states are states with phenomenal intentionality, and not all kinds of intentional properties can be somehow derived from the intentionality of them. Bourget and Mendelovici also think that "Weak PIT is not a version of PIT at all, but rather a weakening of the view."

This phenomenal intentionality is "the intentionality a mental state exhibits purely in virtue of its phenomenal character" (Kriegel, 2013: 2.), and the other idea of PIT is that this kind of intentionality is, at least partly, the source of all other kinds; so phenomenal intentionality has some logical or conceptual priority over other intentionalities. This priority consists in the fact that phenomenal intentionality determines what could be the satisfier of an intentional state. For example, if I see a red tomato on a table before me, then my visual experience has conditions of satisfaction (in the manner of Searle, 1983, Chapter 1), which consists of a particular tomato with a determinate color-shade, a particular table and so on. However, we can ask, why do just these particular objects figure in the conditions of satisfaction of this experience? And the answer has to allude to phenomenal intentionality, which specifies what kind of things the constituents of this condition have to be. The phenomenology of my visual experience constrains the nature of the possible satisfiers. The phenomenal character of my experience has a kind of 'apparent directedness' or 'purported aboutness' (see: Loar, 2003). That is why this aspect of the character can be justifiably called phenomenal intentionality. So, the nature of phenomenal character of experience determines its intentional content in a context in a similar way like the character of an indexical sentence determines the content of the sentence, as David Kaplan famously stated (see: Kaplan, 1989: 505.). 
Phenomenal intentionality plus the context of the experience determines intentional content (see: Lycan, 2008; Strawson, 2008; Farkas, 2008). ${ }^{7}$

Because it is somehow grounded in the phenomenology of experience, many philosophers think also that the content of phenomenal intentional states is narrow. That is, this is a kind of content which me and my phenomenal duplicate - for example my brain-in-a-vat twin - share, regardless of our different physical or social environment. And, as we saw, some of these theorists also think that this narrow content (together with the features of the context) determines the externally constituted wide one (see: Horgan \& Tienson, 2002, Horgan et al., 2004). There are also authors who consider narrow phenomenal intentionality as the only kind of intentionality, thus denying the existence of any wide content (see: Farkas, 2008).

The most urgent task for a phenomenalist is to somehow establish that seemingly non-phenomenal intentional states also have phenomenal character, or that these states can be derived somehow from phenomenally intentional states. The two most obvious kinds of such states are occurrent cognitive states and unconscious intentional states. Unconscious intentional states, include the so-called standing mental states as well. As for occurrent cognitive states, there are many attempts throughout the literature to prove the existence of cognitive phenomenology, that is to prove that cognitive states are among the states with phenomenal intentionality. ${ }^{8}$ The two most elaborated arguments for this thesis are from Strawson (1994), Siewert (1998) and Pitt (2004). Strawson and Siewert argue that some salient phenomenological facts about our understanding, namely some phenomenological contrast-features, can be explained only if we suppose the existence of an 'understanding experience' with a special phenomenal character. For instance, recall the experience of suddenly understanding a sentence with very complex syntactical structure, which appeared senseless earlier; or the experience of grasping an alternative meaning of a syntactically ambiguous sentence (e. g. "Visiting relatives can be boring"); or the difference between how someone, who speaks a certain language, hears sentences uttered in that language, compared to someone who does not speak it. ${ }^{9}$ Pitt, by contrast, argues in a transcendental way: he claims we can gain direct, non-inferential, introspective knowledge of our thoughts and

\footnotetext{
7 This is why I think Walter Ott is mistaken in writing that adherents of phenomenal intentionality have "no story to tell about how phenomenal character represents properties or objects in the world", and that "phenomenal character cannot be an appropriate stopping place unless we understand how it connects a mental state to something in the extramental world." (Ott 2016: 132., italics in the original) There are such stories, as we saw, and these can include even Ott's own solution, namely that the required connection is based on resemblance. What the phenomenalists really miss, in my opinion, is a story about how phenomenal character is sufficient in itself for aiming to connect to something extra-experiential thing. Otherwise, I am sympathetic to Ott's skeptical attitude toward phenomenal intentionality.

8 Chudnoff, (2015: 18.), in contrast, takes the phenomenal intentionality thesis as orthogonal to the thesis of cognitive phenomenology, however just because he defines the former as claiming only the weak version of PIT, in the above sense of the term. For a way of defining cognitive phenomenology see Chudnoff, (2015: 15-19.).

9 Bourget, (2017) also applies some form of argument from contrasting cases, although these are not cases of understanding, but that of grasping a proposition. He defends the so-called "phenomenal theory of grasping" which implies some weak form of cognitive phenomenology, or, as he calls it, liberalism about phenomenal content (ibid 305.).
} 
other cognitive states only if they have phenomenal character. Since we do have such knowledge, cognitive phenomenology does exist.

As for the non-conscious intentional states, there are some popular solutions in circulation in the literature. Although there also exists an explicit non-derivativist standpoint in the relevant literature, ${ }^{10}$ the main line of argumentation aims to prove that non-conscious intentional states derive their intentionality from conscious ones. For example, John Searle argues that unconscious mental states are intentional just in case they are such kind of states that can be conscious, so they are potentially conscious and the intentionality of non-conscious states somehow comes from their conscious counterparts (see: Searle, 1992: 162). Galen Strawson (1994, 2008) argues that only beings with conscious states have also unconscious intentional states, as if the intentionality of the latter ones derived from their position or place in a network of conscious intentional states. Kriegel (2011) states that the unconscious states can become conscious only by some conscious interpretive acts endowed with phenomenal intentionality.

Nevertheless, even if the phenomenalists succeed in proving that every intentional state has phenomenal properties, ${ }^{11}$ they will establish only a permanent cooccurrence of intentional and phenomenal properties. As we saw in the case of the mind-body problem, to claim that these properties coexist is not a substantive statement about the nature of their relationship, and gives no ground to any interdependence and priority thesis. So, phenomenalists would need additional arguments to justify their view.

I myself know of two different kinds of arguments that purport to justify that intentional content somehow depends on phenomenal character. None of them are persuasive, in my view.

The first argument is again due to John Searle. He claims that aspectual shape, that is, the way the intentional object presents itself, is an essential constituent of all kind of intentionality. However, only phenomenal conscious states have real aspectual shape. Unconscious dispositional states have aspectual shape only in the sense that if they were conscious, they would represent their object from such and such aspect. Searle's view is that unconscious states in themselves are not able to do this because they are purely neurophysiological states, in which there is no fact that determines from what aspect, i.e. under what kind of description, they represent their object. (see: Searle, 1992: 162., Kriegel, 2003: 275.).

This is an interesting argument, I think, however, it has a serious deficiency. As UriahKriegel explicitly acknowledges (see: Kriegel, 2003: 280.), if you accepted this argument, you cannot be a physicalist. If a purely neurophysiological state cannot have aspectual shape, but conscious states can, then conscious states are not purely neurophysiological states, neither in a type-identical, nor in a token

\footnotetext{
10 See Mendelovici: "Original intentionality is identical to phenomenal consciousness, and there is no derived intentionality" (Mendelovici 2018: 83.). Nevertheless, Mendelovici advocates a self-ascriptivist theory of derived nonconscious representations, which she clearly distinguishes from any, even derivative, genuine intentionality. See Mendelovici, (2018: 168-69.).

11 For the soundness of arguments for cognitive phenomenology mentioned above, see the first two Chapters of (Chudnoff, 2015).
} 
identical sense. And this seems to be a too high price for accepting the argument, not only for Searle, who present himself as a physicalist, ${ }^{12}$ but for anybody. It does not seem plausible that you can refute physicalism only by analyzing the role and nature of aspectual shape.

The second argument that purports to justify that intentional content depends on phenomenal character is an old one. It proceeds from the difference between original or intrinsic and derived intentionality and claims that only phenomenal consciousness can assign underived original status to an intentional content of a state, so original, logically prior intentionality is always phenomenal intentionality. The argumentation runs as follows. There are countless phenomena in the world to which we can reasonably attribute some kind of 'aboutness' or 'directedness'. It is fair to say that every physical state bears some information about its causes, so, in a sense, every information-bearing state is about its causes, and thus have intentionality. However, we have a strong intuition that most of these states seem intentional only because we can consciously direct our awareness to their causes. Tree rings, linguistic utterances, or printed pictures would have no meaning or 'aboutness' without us, who can understand or interpret them. Consequently, they have intentionality only in a derivative sense, that is, only in virtue of a mind. But where does the intentionality of the mind come from? If mental states also have intentionality only in this derivative sense, then we will need further intentional states from which they can derive their intentionality. And so on, ad infinitum (see e. g.: Kriegel, 2011: 202.). Consequently, if there really is intentionality in the world, there must be some states, the intentionality of which is intrinsic and underived.

Whether or not one finds this argument persuasive, one has to remember that Daniel Dennett has shown a long time ago that this kind of argument has an isought' form. The main reason for the acceptance of the statement that there is original intentionality in the world is nothing else that there ought to be: there must be an 'Unmeant Meaner' in order to stop the regress of interpretations, and thus account for the countless intentional contents in the world (see e. g.: Dennett, 1987: 288.). Therefore, there must be a good answer to the question: what does underived original intentionality consist in, what metaphysical features of some phenomena makes them so special, over and above the need that there must be underived intentionality? Some phenomenalists argue that phenomenal consciousness can do the trick and give rise to original intentionality; in other words: they argue that only phenomenal consciousness can give birth originally to intentionality (see: Kriegel, 2003: 284-85., Kriegel, 2013: 10-11, Mendelovici, 2018: 90-93.). But how can it do this?

There are two known answers to this question. The first one is that of Colin McGinn's, who claims that in phenomenally conscious experiences not only the objects of the experience are represented, but also its subject. Conscious experiences

12 See especially: Searle, (1992: 14-15.). Here and elsewhere Searle tries to defend his thesis that although conscious mental states cannot be identified with purely neurophysiological states, they are caused by neurophysiological states and therefore are higher-order physical phenomena. However, I completely agree with the analysis of Itay Shani, who claims that this defense of physicalism can be successful only at the expense of "obscurantism, where mental states are higher-level features of the brain but are not identical to any brain processes, and where mental properties, though physical, cannot be identified as such." (Shani, 2007: 71., italics in the original). 
are systematic self-representing states. There are not just hosts of the representations, as in the case of every non-conscious intentional states, but have in their very content that it is presented to the conscious subject. Since the concept of intentionality itself contain the subject whose states are directed to other entities, McGinn argues that only conscious experiences could have intentionality in this original sense (see: McGinn, 1988/1997: 299-301., Kriegel, 2003: 284-87., Kriegel, 2007: 325-26.)

The other answer is due to Galen Strawson, who claims that there is no definite answer to the question: what does a state with derived intentionality represent? The state is about its cause, but every state or event have countless many causes. Which link in the chain fill the role of the intentional object? According to Strawson, this question can be answered only by alluding to the phenomenal character of our experiences. He doubts that the known naturalistic accounts of intentionality, that is, the causal, teleological or functional theories could ever solve this problem. As we saw earlier, there is a kind of object with such and such properties in the qualitative aspect of the experience, therefore this qualitative aspect is capable of highlighting the relevant object in the long causal chain (see: Strawson, 1994: 345-51, Strawson, 2008: 296.).

When evaluating this argument, and the two different forms of it, they seem to be based on somewhat vague or opaque considerations. As for Strawson's view that the phenomenal character of an experience can pick out the relevant causal antecedent, it is not clear, how it would achieve doing this. There are known cases where there are more than one potential relevant causal antecedents which, at least prima facie, cannot be discriminated from one another on mere phenomenological grounds, for instance Quine's famous undetached and temporal rabbit parts. Strawson himself says nothing illuminating concerning this question, claiming merely the following:

$[\mathrm{M}] \mathrm{y}$ answer to your question 'How can the quality of experience pin things down determinately' is: It just can. That's how it is. This is what we do. This is the power of the entirely natural phenomenon of conscious thought. (Strawson, 2008: 301-2)

As for McGinn's answer, first of all, his phenomenological description of conscious experience seems inadequate to me. I am not persuaded that there is selfrepresentation in sense experiences. The transparency thesis seems more plausible to me, which claims - as we saw above - that only one kind of properties appears in experience, not two, namely the properties of the perceived object and of the experiencing self. Moreover, similarly to Strawson, McGinn gives us no explanation how phenomenal properties would bring about intentionality. He explicitly says that consciousness itself is a mystical property, which we will never understand, and giving rise to intentionality belongs to its mystical nature (see: McGinn, 1988/1997: 302).

So, we could not get any informative answer to the question of how a phenomenological property could bring about or determine an intentional property. Elijah Chudnoff (Chudnoff, 2015: 136-139.) reaches similar conclusion after carefully investigating some arguments for the phenomenal intentionality thesis, more closely for Property Supervenience Thesis, according to which a state of a person with some definite phenomenological character of $P$ puts the person in some intentional state part of whose content represents the property $P$. Moreover, Chudnoff presents an 
elaborated and prima facie sound argument against phenomenal intentionality in the cases of cognitive states. The core of the argument depends on the premise that the contents of demonstrative, indexical, nominal, natural, mathematical, artifactual, social, normative, and logical concepts do not constitutively depend solely on some phenomenal properties. (Chudnoff, 2015: 141-148.)

Philip Woodward, in the same vein, stresses that reductionist phenomenalists fail to answer two fundamental questions, namely "(1) Why would awareness of phenomenal patterns constitute the presentation of intentional contents, rather than not? (2) $[\ldots]$ What makes it the case that particular objects and properties are presented, rather than others?" (Woodward, 2019: 615.) That is, how can patterns of phenomenal properties instantiated by a subject at a given time give rise to a phenomenal intentional content, and even if they can, how can it be a determinate content, given that there could be many valid interpretations of it? ${ }^{13}$

I think that the apparent lack of informative answers to the question concerning how can phenomenal properties give rise to intentionality is due to the fact that the adherents of phenomenal intentionality are also prone to endorse the tight conceptual connection or coincidence of the concepts of the two properties. Just like the intentionalists, they are inclined to think that the phenomenal quality of an experience is, in other reading, nothing else but the intentional content (or the content and some other intentional properties) of the experience, since both can be characterized as 'the way the world seems to us'. ${ }^{14}$ For example Charles Siewert states that phenomenal states have conditions of accuracy automatically (Siewert, 1998: 217.), and what else could this mean than a commitment to a tight conceptual connection? The drawbacks of Siewert's solution are the same in the case of phenomenalism as they were in the case of intentionalism. In sum, it seems that the situation is exactly the same as it was by intentionalism: the arguments in favor of phenomenalism either prove only some kind of contingent ubiquitous co-occurrence of intentional and phenomenal properties - which is compatible with their independence from each other -, or they prove too much, that is, some a priori conceptual-logical connection, or even conceptual identity.

\section{Conclusion}

My aim in this paper was only destructive: argued that there is no well-established view in the relevant literature about the nature of the relationship between intentionality and phenomenal consciousness. On the one hand, the earlier separatist view

\footnotetext{
13 See also: "[...] there is nothing in the phenomenal patterns themselves that would demand being interpreted in terms of enduring objects, rather than in terms of very short-lived objects - or, for that matter, in terms of property-instances inhering in indiscrete gunk." (Woodward 2019: 615.) Woodward's own proposal is a kind of primitivism which postulates basic phenomenal-intentional properties to the subject's experiential states. In my reading, this solution is not a kind of phenomenalism in the sense of the present paper, since it does not hold the primacy of phenomenal properties, as is acknowledged at a point by Woodward himself: "primitivism does not require the positing of an enigmatic constitutionrelation that is said to hold between phenomenal patterns, on the one hand, and intentional properties, on the other." (Woodward 2019: 618.).

14 Remember that some proponents of phenomenal intentionality also allude to the transparency of experience.
} 
surely seems wrong in the light of many plausible phenomenological insights, which come mainly from the field of perception. It appears quite plausible that intentional and phenomenal properties systematically covary in our mental life, that is, that many mental states, or perhaps all of them, instantiate both kind of properties. On the other hand, while the arguments of inseparatists from both sides are successful in establishing this covariance, they fail to prove the occurrence of some stronger relationship, since what they established is a too strong claim, namely an a priori conceptual connection between, or even identity of the two properties. In sum, these arguments establish only the indifferentist view, rather than inseparatism based on necessary dependence. In other words: even if every intentional state is also a phenomenal state, it does not follow that there is a tight connection between the two properties the state in question equally instantiates..$^{15}$

One could object to this consideration by asking what is actually wrong with the view that there is indeed conceptual connection between intentional and phenomenal properties? There are probably many philosophers who would argue for a tight conceptual connection or even conceptual identity by a priori analysis of these notions. I submit the existence of such connection is implausible. Instead, the opposite view is more plausible: the conceptual analysis of the two notions reveal that they cannot be the same, and cannot even have a common core.

To see this, let's recall that the lack of appearance-reality distinction is the mark of phenomenal properties. The phenomenal feature of a state or event is identical with what it is like to undergo that state or event, therefore, it is conceptually impossible for a mental state to only seemingly bear certain phenomenal feature, but not to bear it in reality. It makes no sense to say that something seemed or appeared $\varphi$ to me, but later it turned out that in reality it just seemed or appeared to me that it seems or appears $\varphi$ to me. Seemings and appearings cannot be iterated.

In contrast, I think, there is nothing in the concept of intentionality, as it is usually grasped in the terms of 'aboutness' or 'directedness', that makes it impossible for the intentional properties of an experience to differ from the apparent intentional properties that present themselves in the phenomenal character of the same experience. There are cases in which the subject consistently think that she has had some experience which had different intentional object than she earlier thought, or which exemplified a different intentional mode than she earlier thought, in which the subject related to the object. ${ }^{16}$ So, the concept of intentionality does not entail the lack of reality-appearance distinction. And since the concept of phenomenal character entails just this, the two concepts cannot be the same, according to Leibniz's Law. Formally, the argument is the following:

\footnotetext{
15 For a similar consideration see Mendelovici (2018: 94. n.17.).

16 For the first, think about the example of the "headachy corridor" attributed to A. J. Ayer and quoted by Farkas (2013: 103.), where the subject ascribes her experience at first to her head (or to nothing at all) and later, retrospectively, to the corridor where the headache always and reliably occurs. For the second, think about some famous romantic novels in which some main character changes her views, again: partly retrospectively, about her own emotions toward another person.
} 
P1 The notion of phenomenal properties conceptually implies the lack of appearance-reality distinction.

P2 The notion of intentional properties does not have such implication.

$\mathrm{C}$ The two notions are distinct.

Intentionality and phenomenality, therefore, are two quite distinct concepts on, so to say, two quite distinct levels. When we describe experiences with phenomenal terms, we characterize them from inside, that is, from the first-person point of view. In contrast to it, when we describe experiences in intentional terms, we do it from the third person point of view. When we attribute phenomenal properties to a state, we refer directly to features we are directly aware of. When we attribute intentionality, we commit ourselves to the view that the relevant state realizes a special abstract structure, i.e. have content, conditions of satisfaction, intentional mode, etc., according to some theory of intentionality (such as Searle, 1983 or Crane, 2001). This realization of such an abstract structure is what can give concrete content to the metaphors of 'aboutness' or 'directedness'.

Let's compare our case to that of water and $\mathrm{H}_{2} \mathrm{O}$. May their concepts be as different as they can, they are equally empirical concepts, in the broad sense of the term. Both "being water" and "being $\mathrm{H}_{2} \mathrm{O}$ " are empirically fully verifiable properties. In contrast, the concept of intentionality is not a wholly empirical or introspective concept. Contrary to some firmly held views in the literature, ${ }^{17}$ I also firmly think that the intentional structure of an experience does not present itself in the phenomenology of the experience: neither the perceiving subject, nor the perceived object in its concrete individuality (that is, in its difference from a perfect duplicate), nor the supposed intentional relation between them appears to me somehow in my experience. I concur with Searle who writes in a more recent paper that "some of the most important logical features of intentionality are beyond the reach of phenomenology because they have no immediate phenomenological reality." (Searle, 2008: 112.) In this sense, phenomenal concepts are observational concepts while intentional concepts are theoretical, and it is difficult to see how the appropriate properties could depend on each other. As it stands, the nature of the purported dependence is entirely unclear from the arguments of the proponents of strong, necessary inseparatism.

\footnotetext{
17 See e.g. "... [W] have a special access to this mental feature [i.e. intentionality] independent of any fuzzy or metaphorical descriptions: We can directly notice it through introspection, at least in some cases." (Mendelovici, 2018: 5., see also Mendelovici \& Bourget, 2020: 561.) Later, she defines such introspectively accessible cases of intentionality as paradigm cases which satisfy two conditions, namely (i) can be noticed introspectively in ourselves and (ii) we are tempted to describe them using representational terms. (See: ibid 6.) Her examples of such intentionality are perceptual experiences and occurrent thoughts. I think, however, that this argumentation is flawed because it confuses the introspective access to some mental states supposed to exemplify intentionality and the introspective access to the feature of intentionality itself. In my opinion we do have some kind of introspective access, for example to perceptual states, but I strongly doubt that we have the same - or other privileged - access to their intentional properties, that is, the properties we tend to describe in representational terms.
} 
Acknowledgments Special thanks are due to Balázs Gyenis, Katalin Farkas, Gábor Forrai, János Tőzsér and Zsófia Zvolenszky for many thoughtful and incisive suggestions on earlier drafts of this paper. The research leading to this paper was supported by OTKA-NKIFH (Hungarian Scientific Research Fund), grant numbers: K109638, K116191, K123839.

Funding Open access funding provided by Eötvös Loránd University.

Open Access This article is licensed under a Creative Commons Attribution 4.0 International License, which permits use, sharing, adaptation, distribution and reproduction in any medium or format, as long as you give appropriate credit to the original author(s) and the source, provide a link to the Creative Commons licence, and indicate if changes were made. The images or other third party material in this article are included in the article's Creative Commons licence, unless indicated otherwise in a credit line to the material. If material is not included in the article's Creative Commons licence and your intended use is not permitted by statutory regulation or exceeds the permitted use, you will need to obtain permission directly from the copyright holder. To view a copy of this licence, visit http://creativecommons.org/licen ses/by/4.0/.

\section{References}

Bailey, A., \& Richards, B. (2014). Horgan and Tienson on phenomenology and intentionality. Philosophical Studies, 167, 313-316.

Balogh, Zs., \& Tőzsér, J. (2013). Much Ado about Nothing: The discarded representations revisited. In E. Images (Ed.), Kondor Zs (pp. 47-66). Herbert von Halem Verlag.

Bourget, D. (2017). The role of consciousness in grasping and understanding. Philosophy and Phenomenological Research, 95(2), 285-318.

Bourget, D., \& Mendelovici, A. (2019). Phenomenal Intentionality. In E. N. Zalta (ed.). The Stanford Encyclopedia of Philosophy (Fall 2019 Edition), URL = https://plato.stanford.edu/archives/fall2 019/entries/phenomenal-intentionality/.

Byrne, A. (2001). Intentionalism defended. Philosophical Review, 110, 199-239.

Chalmers, D. (2004). The representational character of experience. In B. Leiter (Ed.), The Future for Philosophy (pp. 153-181). Oxford University Press.

Chudnoff, E. (2015). Cognitive Phenomenology. Routledge.

Crane, T. (2001). Elements of Mind. Oxford University Press.

Crane, T. (2008). Intentionalism. In A. Beckermann \& B. P. McLaughlin (Eds.), Oxford Handbook to the Philosophy of Mind. (pp. 474-494). Oxford University Press.

Dennett, D. C. (1987). Evolution,error, and intentionality. The Intentional Stance (pp. 287-322). Cambridge: MIT Press.

Farkas, K. (2008). Phenomenal intentionality without compromise. The Monist, 91, 273-293.

Farkas, K. (2013). \&nbsp;Constructing a world for the senses. In U. Kriegel (Ed.), Phenomenal Intentionality (pp. 99-115). OUP.

Harman, G. (1990). The intrinsic quality of experience. In J. Tomberlin (Ed.), Philosophical Perspectives 4. (pp. 31-52). Ridgeview Publishing.

Horgan, T., Tienson, J., \& Graham, G. (2004). Phenomenal intentionality and the brain in a Vat. In R. Schantz (Ed.), The Externalist Challenge: New Studies on Cognition and Intentionality (pp. 297318). de Gruyter.

Horgan, T., \& Tienson, J. (2002). The intentionality of phenomenology and the phenomenology of intentionality. In D. Chalmers (Ed.), Philosophy of Mind: Classical and Contemporary Readings (pp. 520-533). Oxford University Press.

Jackson, F. (2005). The case for a priori physicalism. In C. Nimtz \& A. Beckermann (Eds.), Philosophy - Science - Scientific Philosophy, Main Lectures and Colloquia of Gap 5, Fifth International Congress of the Society for Analytical Philosophy. (pp. 251-285). Mentis.

Kaplan, D. (1989). Demonstratives. An essay on the semantics, logic, metaphysics, and epistemology of demonstratives and other indexicals. In J. Almog, J. Perry, \& H. Wettstein (Eds.), Themes from Kaplan (pp. 481-564). Oxford University Press. 
Kriegel, U. (2002). Phenomenal content. Erkenntnis, 57, 175-198.

Kriegel, U. (2003). Is intentionality dependent upon consciousness? Philosophical Studies, 116, 271-307.

Kriegel, U. (2007). Intentional inexistence and phenomenal intentionality. Philosophical Perspectives, 21, $307-340$.

Kriegel, U. (2011). The Sources of Intentionality. Oxford University Press.

Kriegel, U. (2013). The Phenomenal intentionality research program. In U. Kriegel (Ed.), Phenomenal intentionality. (pp. 1-26). Oxford University Press.

Loar, B. (2003). Phenomenal intentionality as the basis of mental content. In M. Hahn \& B. Ramberg (Eds.), Reflections and Replies: Essays on the Philosophy of Tyler Burge. (pp. 229-258). MIT Press.

Lycan, W. (2008). Representational theories of consciousness. In E. N. Zalta (ed.). The Stanford Encyclopedia of Philosophy. URL = http://plato.stanford.edu/archives/fall2008/entries/consciousness-repre sentational/.

McGinn, C. 1988/1997. Consciousness and content. Proceedings of the British Academy 74: 219-239., reprinted In N. Block, O. Flanagan, G. Güzeldere (eds.), The Nature of Consciousness. MIT Press. pp. 295-307.

Mendelovici, A. (2018). The Phenomenal Basis of Intentionality. Oxford University Press.

Mendelovici, A., \& Bourget, D. (2020). Consciousness and intentionality. In U. Kriegel (Ed.), Oxford Handbook of Consciousness. (pp. 560-585). Oxford University Press.

Ott, W. (2016). Phenomenal intentionality and the problem of representation. Journal of the American Philosophical Association, 131, 145.

Pitt, D. (2004). The phenomenology of cognition, or, what is it like to think that P? Philosophy and phenomenological research, 69, 1-36.

Pitt, D. (2009). Intentional psychologism. Philosophical Studies, 146, 117-138.

Rosenthal, D. (1994). Identity theories. In S. Guttenplan (Ed.), A Companion to the Philosophy of Mind. (pp. 348-355). Basil Blackwell.

Searle, J. (1983). Intentionality: An Essay in the Philosophy of Mind. Cambridge University Press.

Searle, J. (1992). The Rediscovery of the Mind. MIT Press.

Searle, J. (2008). The phenomenological illusion. Philosophy in a New Century. (pp. 107-136). Selected Essays.

Shani, I. (2007). Consciousness and the First Person. A Critical Appraisal of Searle's Connection Principle. Journal of Consciousness Studies, 14(12), 57-91.

Siewert, C. (1998). The Significance of Consciousness. Princeton University Press.

Strawson, G. (1994). Mental Reality. MIT Press, Bradford Books.

Strawson, G. (2008). Real intentionality 3: Why intentionality entails consciousness. Real Materialism and Other Essays (pp. 281-305). Oxford University Press.

Tye, M. (1995). Ten Problems of Consciousness. MIT Press, Bradford Books.

Woodward, P. (2019). Phenomenal intentionality: Reductionism vs. primitivism. Canadian Journal of Philosophy, 49(5), 606-627.

Publisher's Note Springer Nature remains neutral with regard to jurisdictional claims in published maps and institutional affiliations. 